\title{
Danza Tradicional San Benito de Timotes Patrimonio de Identidad Cultural
}

Autora: Yajaira Esperanza Araujo Araujo Universidad Fermín Toro, UFT araujoyajairaunica@hotmail.com Lara, Venezuela https://orcid.org/0000-0003-0133-8495

Resumen

Las fiestas populares tradicionales, son una muestra característica del Patrimonio Histórico Cultural y por ende de la identidad cultural de un pueblo. Constituyen un suceso de obligada mirada en el tiempo, una visión integral como catalizadora de las expresiones identitarias. Se aborda el presente ensayo que tiene como propósito dar a conocer la fiesta patronal de San Benito de Timotes como legado histórico y patrimonio cultural de la región merideña, afianzando y refundando la tradición venezolana. El estudio fue abordado como trabajo de campo crítico reflexivo de naturaleza cualitativa y revisión bibliográfica para contrastar e interpretar realidades. Referentes estudiados que sustentan el ensayo: Ley de Protección y Defensa del Patrimonio Cultural (1993) el cual establece la preservación, defensa y salvaguarda de todas las obras, conjuntos y lugares creados por el hombre o de origen natural, que se encuentren en el territorio de la República, y que por su contenido cultural constituyan elementos fundamentales de nuestra identidad nacional. En el desarrollo del trabajo se plantean aspectos fundamentales como el patrimonio cultural, las fiestas tradicionales y la manera de proyectar la cultura, además, los elementos que identifican la danza de San Benito y la convierten en reflejo de identidad cultural para las generaciones futuras.

Palabras clave: historia; patrimonio cultural; identidad. 


\title{
Traditional Dance San Benito of Timotes Heritage of Cultural Identity
}

\begin{abstract}
Traditional folk festivals are a characteristic feature of the Cultural Historical Heritage and therefore of the cultural identity of a town. They constitute an event of obligatory look in time, an integral vision as a catalyst for identity expressions. The present essay is addressed with the purpose of making known the patron saint festival of San Benito of Timotes as a historical legacy and cultural heritage of the Merida region, strengthening and refounding the Venezuelan tradition. The study was approached as reflexive critical field work of qualitative nature and bibliographic review to contrast and interpret realities. Referents studied that support the essay: Law of Protection and Defense of Cultural Heritage (1993) which establishes the preservation, defense and safeguarding of all works, groups and places created by man or of natural origin, that are in the territory of the Republic, and that for their cultural content constitute fundamental elements of our national identity. In the development of work, fundamental aspects such as cultural heritage, traditional festivals and the way of projecting culture are raised, as well as the elements that identify the San Benito dance and turn it into a reflection of cultural identity for future generations.
\end{abstract}

Keywords: history; cultural heritage; identity. 


\section{Introducción}

Las fiestas tradicionales constituyen diversas formas de abordar el Patrimonio Cultural y su relación con la Identidad de los pueblos, uno de los aspectos relevantes que engloban este patrimonio son las fiestas religiosas 0 fiestas patronales que vienen a reflejar la espiritualidad del gentilicio de un lugar determinado. Es evidente que el legado histórico-cultural, de nuestra sociedad pareciera que cada vez más pierde sentido, frente a un fenómeno que cobra nuevas fuerzas como es la Globalización.

Ante esta realidad global, en Venezuela se evidencia una falta de empoderamiento y de sentido de pertenencia en las nuevas generaciones hacia la identidad y la conciencia histórica cultural producto de la transculturación, se ha visto amenazada por la posmodernidad que ha influenciado de forma negativa en la conciencia de los jóvenes quien han querido sustituir las costumbres que caracterizan la esencia del gentilicio venezolano dejando a un lado lo tradicional, sin embargo, en algunos pueblos del país específicamente en la población de Timotes, aún se conserva el patrimonio histórico y cultural constituido por mitos, leyendas, fiestas patronales y religiosas; razón por la cual el artículo tiene como propósito dar a conocer la fiesta patronal de San Benito de Timotes como legado histórico y patrimonio cultural de la región merideña, afianzando y refundando la tradición venezolana.

El presente ensayo, recoge historia de un pequeño terruño venezolano de todo aquello que pueda representar el patrimonio de generación en generación como una herencia de los pobladores de Timotes estado Mérida a través de la fiesta patronal de San Benito. La temática está centrada en la experiencia vivencial de la Autora como trabajo de campo sociocultural realizado en el año 2015, con esta experiencia se pretende sensibilizar al lector y transportarlo a un mundo donde aún prevalece eso que llamamos identidad amor a lo nuestro, simbolizado por una danza como valor moral y espiritual del 
patrimonio cultural de los habitantes mirandinos.

En tal sentido, Martínez (2018): plantea que el patrimonio cultural, "da relevancia e importancia a la historia regional, los sitios históricos, monumentos, museos, galerías, personajes vivientes de la localidad, entre otros aspectos inherencia a la cultura" (pág. 6). Interpretando lo que señala la autora, el patrimonio cultural viene afianzar los valores, las manifestaciones, costumbres y tradiciones populares de un sector determinado, por lo tanto, abarca las experiencias, vivencias que tiene el individuo sobre el arsenal cultural que tiene cada entidad o región.

\section{Desarrollo}

\subsection{Patrimonio Cultura}

Para Bonfil (1997): Patrimonio Cultural "es el conjunto de símbolos, valores, actitudes, habilidades, conocimientos, significados, formas de comunicación y organización sociales, que hacen posible la vida de una sociedad determinada y le permiten transformarse y reproducirse como tal, de una generación a las siguientes" (pág. 29). Cuando se habla de patrimonio cultural de un pueblo, a lo que se refiere es, precisamente, a ese acervo de elementos culturales que una sociedad determinada considera suyos y de los que echa mano para perpetuarse en el tiempo.

De hecho, para los pobladores de Timotes esta manera de entender el patrimonio cultural lo materializan en las fiestas patronales como prácticas de la religiosidad local y acervo histórico donde se mezclan y fusionan actos festivos y lúdicos con creencias y actos religiosos, tal como lo señala Rodríguez (2000): "Las fiestas patronales entrarían dentro de lo que podríamos llamar prácticas de la religiosidad local" (pág. 11).

\subsection{Georreferenciación de Timotes}

Timotes está ubicado en el Municipio Miranda del estado Mérida, a una 
altitud de 2025 M.S.N.M. sobre una sucesión de terrazas que formó el río Motatán en el transcurso de los varios de miles de millones de años, su temperatura media es de 15ำ es una de las poblaciones más importante del páramo y de mayor número de habitantes. Este municipio forma parte de los 23 Municipios del Estado, con una superficie de 408 km², su población para el censo Municipal del 2011 se ubicó en 23.966 habitantes, está dividido en cuatro parroquias, Andrés Eloy Blanco, La Venta, Piñango y su capital Timotes.

Haciendo referencia a su historia; Espinoza (1992): señala, "una historia remota al año 1600 cuando los conquistadores, civiles y religiosos europeos llegaron a esta tierra fundando la capilla de paja de Timotes" (pág. 6). Bajo la información suministrada del mismo autor; antiguamente fue bautizado por los naturales como sitio antiguo de Mucurujún. Aquí vivieron, por años grupos aborígenes de estirpe Timote y Cuica, entre ellos destacaron las parcialidades: Mucuxamán, Mucuguá, Quindorá, Chiquimpú, Mucuyupú, Muarcé, Chijos, Mucumbás, Chicuá y otras que vivieron de la agricultura, sembrando papa y maíz en los diversos campos que integran estas comarcas. El Municipio en la historia cultural es reconocido por sus fiestas patronales: Santa Lucia y San Benito que se celebran en el mes de diciembre.

\subsection{Recorrido Histórico por su tradición y culto al Santo Negro San Benito}

\subsubsection{Culto al Santo}

El culto de San Benito que en Venezuela tuvo su origen en el sur del lago de Maracaibo y actualmente se expresa como una danza y manifestación tradicional en muchos pueblos del país incluyendo el hermoso terruño merideño; donde las fiestas de San Benito muestran gran variedad en sus danzas, vestimentas, tonadas y tradiciones con respecto a las realizadas en otras regiones del país. No obstante, coinciden en parte con estas en la música 
de origen africano, en las danzas de origen indígena, así como en el discurso oficial y la representación real de la fiesta. En la descripción que se hace de este santo en Timotes, puede observarse que se focaliza el origen de la fiesta en el antiguo resguardo indígena de la zona.

\subsubsection{Timotes pueblo de fe}

El sonido de los tambores y de las maracas al unísono, proclaman el inicio de la gran fiesta del santo de la bondad. La ferviente devoción que tienen los pobladores de Timotes y zonas vecinas para con San Benito de Palermo, es un verdadero ejemplo de fe. Esta es una tradición que representa el sentir del gentilicio Mirandino recordando la época de la colonización y como surgieron del dominio de los españoles, con la fe puesta en San Benito, y el valor de la religiosidad de sus habitantes.

Los devotos a San Benito de Timotes comparten una de las fiestas más fervorosas dentro de sus tradiciones que se han conservado intacta a través de los años donde cada 29 de diciembre, los religiosos visten sus trajes multicolores y se pintan el rostro de negro, para bailar y darle las gracias por los favores recibidos. Desde las primeras horas de la mañana la devoción por el Santo Negro se hace sentir con el repicar de las campañas.

Los giros y vasallos se levantan desde bien temprano para rendir tributos a su Santo y participar en la misa solemne, el repicar de los cueros del tambor, mucho colorido, el sonido de las maracas y un contagioso fervor religioso inundan las calles de este pintoresco pueblo. Desde los más pequeños hasta los hombres de la tercera edad, jóvenes, niños y niñas recorren las calles del pueblo en la tradicional procesión a San Benito de Palermo.

Para dar mayor relevancia al ensayo, la investigadora realizó el siguiente Trabajo de Campo como Proceso de Investigación Sociocultural, contiene el Plan de Acción y la sistematización de la información, en el cual se 
describen las acciones ejecutadas por la Autora. Proceso que permitió registrar los acontecimientos tal como se fueron dando en el transcurso del estudio.

Tabla nro. 1: Plan de acción.

\begin{tabular}{|c|c|c|c|c|}
\hline Actividad & $\begin{array}{l}\text { Técnica de } \\
\text { abordaje }\end{array}$ & $\begin{array}{l}\text { Intencionalidad } \\
\text { dialéctica }\end{array}$ & Recursos & $\begin{array}{l}\text { Lugar y } \\
\text { fecha }\end{array}$ \\
\hline $\begin{array}{l}\text { Participación en } \\
\text { la fiesta patronal } \\
\text { tradicional San } \\
\text { Benito de } \\
\text { Timotes. } \\
\text { Entrevistas a la } \\
\text { directiva de la } \\
\text { sociedad y } \\
\text { vasallos de las } \\
\text { comparsas } \\
\text {-Reflexiones y } \\
\text { sistematización. }\end{array}$ & $\begin{array}{c}\text { Visita a las } \\
\text { comparsas. } \\
\text { Participación } \\
\text { en fiesta } \\
\text { patronal. }\end{array}$ & $\begin{array}{c}\text { Valorar el } \\
\text { patrimonio } \\
\text { histórico de saber } \\
\text { cultural que } \\
\text { identifica la } \\
\text { población de } \\
\text { Timotes. }\end{array}$ & $\begin{array}{c}\text { Investigadora, } \\
\text { vasallos de } \\
\text { San Benito. } \\
\text { Cámara } \\
\text { fotográfica, } \\
\text { cuaderno de } \\
\text { nota. }\end{array}$ & $\begin{array}{c}\text { Población } \\
\text { de } \\
\text { Timotes } \\
\text { del } 26 \text { al } \\
29 \text { de } \\
\text { diciembre } \\
\text { del } 2015 .\end{array}$ \\
\hline
\end{tabular}

Fuente: La Autora (2015).

\section{Sistematización de la fiesta patronal en honor a San Benito}

El día 26 se hace acto de presencia en plaza Bolívar para deleitar con el desfile inaugural de las festividades, se evidencian Bandas Show tocando, luego les sigue los estandartes movilizados por los socios, encabeza el desfile una carroza que traslada el Santo Negro, carros vestidos con turbantes y cintas, tamboreros y mucha algarabía por el pueblo, asimismo morteros que vienen y van. Al dialogar con uno de los miembros de la comparsa "Los Apaches" expresa; esto del desfile es nuevo hace como siete años se comenzó por iniciativa del Sr. Jhonas, vicepresidente de la Sociedad, inicialmente para dar más alegría a las fiestas y hoy día se está convirtiendo en tradición al forma parte del Programa de las fiestas.

Posteriormente, el día 27, se da apertura a la actividad religiosa, se viste 
el Santo en la Capilla con un manto muy bien detallado de pedrería, al preguntarle a la Sra. Cecilia, secretaria de la Directiva el significado del manto ella responde; por tradición se le cambia el manto todos los años por promesa, este año le tocó a la Sra. Yosbaly. Luego de vestir el santo y adornar su carruaje lo colocan al frente de los feligreses; los vasallos se colocan de rodillas venera la imagen e inician el rezo de la novena.

Con base a lo expuesto, según Heinze (2010): el dogma católico dice: "Está permitido y es beneficioso venerar las imágenes de los santos" (pág. 15). Tal aseveración afirma el testimonio de fe y el sentir de cada uno de sus vasallos que adoran la imagen venerándola con un respeto único.

Figura nro. 1: Novena a San Benito.

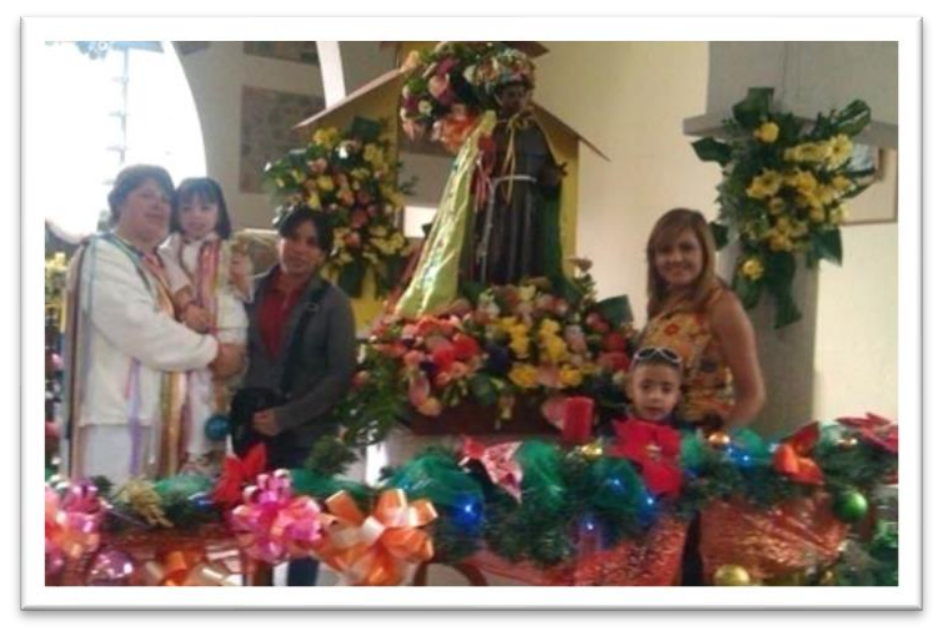

Fuente: La Autora (2015).

El día 28, alrededor de las 7 de la noche, comenzó la celebración. Se da inicio con una misa ofrecida para todos los vasallos de la sociedad de San Benito muertos y vivos y al concluir esta se dio la Bajada de San Benito, entre música danza y morteros donde se trasladó el santo desde su capilla hasta el templo principal. En voz del Sr. Emiro giro de la comparsa Guillermo Franco; 
esta actividad consiste en una procesión al son de la música, la cual se hace presente dentro de la capilla, en el momento que finaliza la misa el santo es llevado en hombros hasta la salida y continua el recorrido con danza tambor y morteros hasta llegar a la Iglesia, acota el señor; es un compromiso con San Benito y una costumbre para nuestro pueblo la bajada del santo.

Boas (1964): señala, "la religión son las actitudes y actividades que giran en torno a lo que se considera sagrado en una comunidad" (pág. 167). En tal sentido, las tradiciones y costumbres desempeñan un papel muy importante las cuales han permanecido con el paso del tiempo, las mismas contribuyen a su conservación. Con base a la posición del autor, los pobladores de Timotes viven y exteriorizan el legado de sus antepasados, lo cual constituye su herencia en lo religioso, espiritual, histórico y sociocultural que los caracteriza como pueblo y su gente.

Al concluir la actividad, la autora aprovecho la oportunidad para entrevistar algunos de los miembros de la Sociedad de San Benito; ¿En qué año se fundó la Sociedad y quienes fueron sus primeros vasallos o socios?, responde la Secretaria; La sociedad de san Benito fue registrada en el año 1944, sin embargo, según la tradición oral, la fiesta se remonta a principios de 1900, como tradición heredada de los aborígenes que habitaron el resguardo indígena, este antiguo resguardo se denomina actualmente "la Mancomunidad indígena Timotes"; entre los fundadores han dicho en reuniones, que Leónidas Simancas fue el primer Presidente de la Sociedad y los primeros vasallos fueron: Silvio Ocanto, Ramón Araujo, el Cacique de la Mancomunidad y Guillermo Franco.

Con respecto a lo expresado, la UNESCO (2011): según el folleto entregado por el Ministerio del Poder Popular para la Educación a las Escuela Bolivarianas con Comunidades Indígenas, en Asamblea General, se declara Año Internacional de los Afrodescendientes, donde plantea, "la promoción de un mayor respeto y conocimiento de la diversidad, su herencia y su cultura" 
(pág. 2). Lo expresado permite entender la importancia del saber ancestral dentro de una comunidad lo cual debe ser plasmado como parte de la historia de la enseñanza oral y es a través de estos estudios que se puede recopilar y perpetuar tal información y formar una especie de enciclopedia del saber colectivo.

Motivados todos se continúan con la entrevista, ¿Cuántas comparsas danzan a San Benito? A lo que la secretaria continúa dando respuesta; Existen tres grupos marcados de comparsas que bailan San Benito, 1). Grupo de giros. La comparsa de la Basílica, de la Capilla, las Lajitas, Giras Pequeñas, Santa Eduviges, Fernando Trupia, Comparsa Guillermo Franco Mixta; 2). Grupo de negros (la comparsa Don Cristóbal y Diana, la comparsa Pio Franco de Timotes, Romería San Benito, Juan Pablo II, Los Negros de Palermo).

Persiste la Sra. Cecilia, y 3). Grupo de indígenas (la comparsa los Marrones de Piedra Gorda, los Comanches Apaches de los Llanitos, los Timoto-Cuicas, Comparsa El Paramito), otra pregunta relevante fue ¿Puede hacer el favor de explicar el vestuario, las pinturas que usan en su piel para hacerse las figuras y los instrumentos para tocar?, se observa un gesto de sonrisa y toma la palabra el presidente de la Sociedad manifestando; En las danzas participan varios grupos: los giros visten de blanco con cintas de seda pegadas a sus camisas, y usan un turbante, los negros llevan sus caras pintadas de negro y visen de negro con una cinta roja en la frente, los marrones van de marrón con cintas rojas y los indios decoran sus caras y brazos con flechas y símbolos de guerra. Todos llevan una maraca en la mano derecha lo que les indica el tipo de danza.

Prosigue el Sr. Antonio Duarte; Hoy, los grupos de danzantes que representan y encarnan los Aborígenes Timotes y Cuicas (Comparsa Timotocuica) y las distintas Comparsas de Negros, danzan al compás de tambores excesivamente sonoros, precisándose el retumbar de los cueros. Los instrumentos que normalmente se ejecutan son el violín, el cuatro, las 
maracas y los tambores, unos bailan con sebucán, otros con cuerda y la comparsa más numerosa y llamativa en este tiempo es la de Hugo Becerra que se caracteriza por el uso de un chaleco con cuerdas utilizado por el vasallo Mauricio.

Pide la palabra el Joven Mauricio vocal de la sociedad y vasallo de la comparsa, relata; yo soy quien tiene la responsabilidad de llevar el chaleco en toda la procesión, fue creada en 1989 es la comparsa más conocida dentro de las comparsas de "Negro" el fundador Javier Antonio "El Negro" Ramírez. La danza esta compuestas por dos combinaciones: la primera es la contradanza o bailes sueltos realizando figuras en 2 columnas como cruces, círculos grandes y pequeños, el tábano donde cada columna va recogiendo cada uno de los vasallos donde se realiza figuras en parejas frente al Santo Negro.

Continua el joven, la segunda consiste en tejerme y destejerme este chaleco que sirve como asta o palo, realizamos los siguientes tejidos; la crineja (en variante de 2, 3, 4 y 5), la estrella, el chaleco, la telaraña, la cruz, la mariposa, el alambre, los invito para mañana a ver nuestra danza, finaliza el relator.

El día 29, a eso de las nueve de la mañana, se concentraron en la plaza Miranda (frente a la capilla de San Benito) gran cantidad de Giros y Giras, Negros e indios y grupos mixtos. Cada comparsa o grupo empezó a danzar, posteriormente bajaron todos en procesión por la Avenida Bolívar rumbo a la Basílica, subieron a San Benito hasta la capilla y aproximadamente entre diez y treinta comenzó la misa, al concluir la misa cada comparsa bailo por separado por las principales avenidas del pueblo, llama la atención que habían personal que bailaban descalzas en acción de gracias por favores recibidos de San Benito, danzaron hasta las ocho de la noche cuando llegó la última comparsa a la Plaza Miranda, rindiendo culto al Santo Negro.

Al respecto, Espinoza (2008): señala, "las comparsas de San Benito, se han encargado de difundir por distintas regiones del país, la esencia cultural- 
folclórica de Timotes" (pág. 31). Efectivamente, estas comparsas con sus danzas han logrado impresionar a los miles de seguidores que años tras años visitan a nuestro Timotes, el éxito radica en sus genuinas representaciones, innovaciones marcadas por la creatividad mostrada en cada baile, los cuales resulta todo un ritual que nos sumerge entre la magia negroide y la mismísima poesía aborigen.

\subsection{Aspectos relevantes de la Danza}

\subsubsection{La Danza como ofrenda principal}

En la fiesta de San Benito en Timotes, aparentemente, no existe una marcada diferencia entre el San Benito oficial y el no oficial, como ocurre en el sur del lago y otras zonas del occidente venezolano, en las que el consumo de licor es la causa fundamental de las diferencias entre iglesia y pueblo. Manifiesta el entrevistado maestro de pueblo y Director de la Casa de Cultura "Don Jesús María Espinoza Becerra" Jonathan Toro, que es importante señalar; que la danza al santo en Timotes nunca es bañado de licor, como ocurre en otras zonas de la región.

Cuando se realiza la fiesta de San Benito. El pueblo de Timotes se evoca al santo como un ser supremo, los valores giran en torno a un mundo sobre natural, San Benito es el único ser capaz de traer prosperidad y bienestar, además de proporcionar fuerza a todos los integrantes de las comparsas para danzar por espacio de tantas horas seguidas.

El día 29, los integrantes de las diferentes comparsas se comienzan a preparar desde las cinco de la mañana, ya sea en sus casas, en los sitios donde han ensayado desde octubre. Los danzantes que vienen de caseríos cercanos se concentran en un sitio previamente acordado, donde los recoge un camión que los llevara a Timotes.

Posteriormente, a eso de las nueve de la mañana, se encuentran concentrado en la plaza Miranda (frente a la capilla de San Benito) gran 
cantidad de Giros y Giras, Negros e indios y grupos mixtos. Cada comparsa o grupo empieza a realizar ensayos con las diferentes figuras y tejidos, hasta aproximadamente entre diez y treinta empieza la misa, al concluir la misa la comparsa mayor realiza la ceremonia del "saludo" ejecutada por los Giros más antiguos, que consisten en danzar hacia atrás semi inclinado, dándole la cara al santo, nunca la espalda, levantando y bajando el brazo derecho haciendo sonar la maraca que tiene en la mano, durante esta procesión realizar figuras (contradanza) y se da inicio a la procesión central danzando todas las comparsas por las principales avenidas del pueblo.

\subsubsection{Recorrido}

La precesión recorre las principales vías de Timotes (Av. Bolívar y Av. Miranda), se inicia en la Plaza Miranda frente al Santuario de San Benito, dobla a la izquierda para bajar por la Avenida Bolívar hasta el pie del pueblo y retornan por la Avenida Miranda hasta llegar nuevamente al santuario, este recorrido dura entre seis y siete horas aproximadamente. En el recorrido, los socios con mayor jerarquía en la sociedad, así como otras personas por promesas o favores concedidos llevan la imagen del santo $y$, van precediendo la procesión. Siguen las diferentes comparsas son sus respectivo vasallos, danzas y músicos.

\subsubsection{Las comparsas}

Son muchas las comparsas las que acompañan a San Benito, cada una tiene sus reliquias, sus tambores, realizan sus bailes y utilizan vestimentas de diferentes colores para diferenciarse una de otra. Ellas se reúnen en la plaza Bolívar a esperar a que los sacerdotes que celebrarán la misa salgan para acompañarlos hasta la plaza Miranda que es donde se hacen los actos centrales.

En ese momento, cuando está todo listo, el cielo se llena de música con 
el repique de campanas de las dos iglesias y es así como se da inicio a la caminata, donde hombres, mujeres y niños recorren con sus reliquias y van pagando la promesa que la han hecho a San Benito con anterioridad.

Sin lugar a dudas que la presencia de tanta gente en las fiestas de San Benito, demuestra la gran devoción que tiene esta comunidad por el Santo Negro, desde muy niños los hombres y mujeres de la población comienzan a manifestar esa fe por el santo y es por eso que la sociedad cuenta con más de dos mil socios.

Entre las comparsas más conocidas se encuentran: la comparsa de la Basílica, de la Capilla, Las Lajitas, Giras Pequeñas, Santa Eduviges, Romería San Benito, Don Cristóbal y Diana Alarcón, Juan Pablo II, Los Marrones de Piedra Gorda, Fernando Trupia, Los Negros de Palermo, Comparsa Guillermo Franco Mixta, Comparsa El Paramito, entre otros.

\subsubsection{Algunas comparsas}

Comparsa Los negros: La comparsa de Los Negros es una de la más antigua de Timotes. Su fundación data del año 1958, así lo confirmó el señor Mauricio Araujo, quien junto a Juan Ramírez González fueron los fundadores, el primer año apenas danzaban seis personas, años tras años fueron integrándose nuevos miembros y se le agrego nuevas gaitas (nombre dado a las figuras).

Comparsa de Hugo Ramón Becerra: Fue creada en el año 1989, es considerada como la comparsa más conocida dentro de las comparsas de "Negro" su fundador y primer director Javier Antonio "El Negro" Ramírez, esta comparsa ha logrado impactar a los miles de seguidores que años tras años visitan a Timotes, el éxito radica en sus genuinas representaciones, innovaciones marcadas por la creatividad mostrada en cada danza, las cuales resultan todo un ritual que nos sumerge entre la magia negroide y la mismísima poesía aborigen. 


\subsubsection{Memorias danzantes de corazón}

María Oliva, integrante de la Sociedad de San Benito de Palermo de Chachopo, Mérida, le baila a San Benito desde hace 4 años movida por la fe y por seguir los pasos de su padre quien en sus tiempos celebraba al Santo.

Francisca Plaza, integrante de la Sociedad de San Benito de Palermo de Chachopo, Mérida, lleva ocho años bailándole a San Benito por promesa familiar.

José Moreno, padre de dos niñas, una llamada María José de ocho años y Norelis del Valle de seis años, Moreno indicó que una promesa fue el motivo de unirse al baile de San Benito, además aseguró que sus hijas también bailan y lo hacen desde que tenían un año de vida, apenas comenzando a caminar, ha tratado de inculcarles la devoción por San Benito con mucho respeto y con bastante fe.

Cabe destacar la presencia de muchos niños como danzantes, además las comparsas presenten se dividían, entre jóvenes, mujeres devotas, hombres devotos, grupos de familias, o por regiones, todos con un mismo fin, rendirle tributo a San Benito.

Figura nro. 2: Reliquia San Benito de Timotes Municipio Miranda, Mérida.

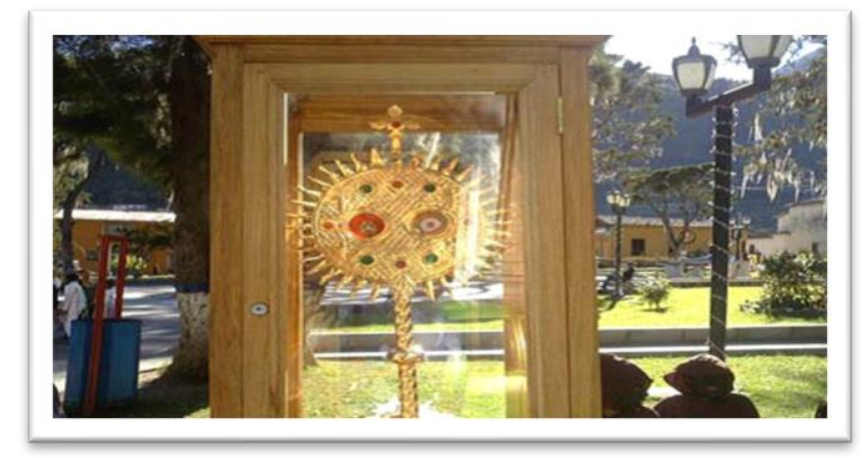

Fuente: La Autora (2015).

Hugo González, (Informante) profesor de esta localidad siendo uno de los pioneros para la instauración de la sagrada reliquia en Timotes, manifestó; 
que recientemente la feligresía católica de esta localidad, celebró por todo lo alto un año más de la llegada de la sagrada reliquia a Timotes, así mismo, expresa que la reliquia es auténtica y fue traída al pueblo por mi hermano Elisaúl y yo, con el apoyo del padre Olivo León, párroco de la Parroquia Timotes para esa época. La reliquia consta de un trozo de piel del Santo de Palermo, que fue traída desde Italia.

Es por lo que tiene una significación muy especial para la región y los venezolanos, porque en cualquier rincón de la geografía nacional, está presente San Benito, llamando a ser constructores de la fraternidad, el amor y trabajar por el bien común. Ese mensaje invita a reflexionar como a través de la devoción se refleja un pequeño pueblo lleno de bondad y humildad hacia sus semejantes.

\section{Conclusión}

El Patrimonio Cultural centrado en la fiesta patronal de San Benito de Timotes en está constituido por la actividad religiosa más relevante de sus pobladores expresa las creencias, tradiciones, religiosidad, lenguajes, arte, ritos, costumbres que permiten a sus habitantes expresar su espiritualidad y amor a sus tradiciones como ejemplo de vida. Asimismo, amalgamar la identidad nacional permite conocer los valores tradicionales con que se identifica los pobladores y especialmente conservar la idiosincrasia de los pueblos, así mismo, la importancia del saber ancestral dentro de una comunidad lo cual debe ser plasmado como parte de la historia de la enseñanza oral y es a través de estos estudios que se puede recopilar y perpetuar tal información y formar una especie de enciclopedia del saber colectivo.

La experiencia vivencial del Culto a San Benito, se enmarca dentro de lo que se podría llamar una cultura de Resistencia en América, la cual surge de un extraordinario proceso creativo que superó las barreras impuestas por 
la esclavitud. La discriminación, los prejuicios y el amor a su acervo histórico cultural, valor a la identidad aborigen, conocimiento ancestral y registro histórico-cultural de la localidad.

\section{Reflexión final}

Estudiar y conocer la idiosincrasia y patrimonio de nuestros pobladores venezolanos, conlleva a identificar las raíces de los saberes y haceres ancestrales de las regiones del país, por ende, se debe valorar, cuidar y resguardar todo aquello que ha transcurrido con el pasar del tiempo como identidad nacional, se trata de la historia oral, escrita, el conocer, el ser y el hacer de los pueblos; vivenciar y transmitir lo que realmente somos como venezolanos y darnos a conocer a través de la cultura en las demás naciones del mundo permitirá mantener y fortalecer los valores ancestrales que nos caracterizan como pueblo.

\section{Referencias}

Bonfil, G. (1997). Nuestro patrimonio cultural: un laberinto de significados. El Patrimonio Cultural de México. Tomo I. México: Consejo Nacional para la Cultura y las Artes-Fondo de Cultura Económica, pág. 29.

Boas, F. (1964). Cuestiones fundamentales de Antropología Cultural. Buenos Aires, Argentina: Ediciones Solar-Hachette S.A., pág. 167.

Espinoza, J. (1992). Historia Mínima de Timotes. Venezuela: I Edición. Centro Editorial de la Escuela de Comunicadores Populares "Mario Keplun".

Espinoza, J. (2008). Timotes Paraíso de los Andes. Venezuela: Guía Turística. Impresión Talleres Universo Grafico C.A.

Heinze, T. (2010). Respuestas a mis Amigos Católicos. California, EE.UU.:

Edición Kindle, Chick Publications. 
Ley de Protección y Defensa del Patrimonio Cultural (1993). Titulo I. Del Patrimonio Cultural, Capítulo I, Disposiciones Generales, Art. 1 y 2. Gaceta Oficial de la República de Venezuela, Numero 4.623 Extraordinario del viernes 3 de octubre. Caracas, Venezuela: El Congreso de la República de Venezuela.

Martínez, C. (2018). Participación Comunitaria Orientada hacia la Valoración del Patrimonio Cultural. Revista Scientific, 3(8), 290-300. Recuperado de:

https://doi.org/10.29394/Scientific.issn.2542-2987.2018.3.8.15.290-300 Rodríguez, S. (2000). Religión y fiesta. Antropología de las creencias y rituales de Andalucía. Sevilla, España: Signatura Demos.

UNESCO (2011). Año Internacional de los Afrodescendientes. Madrid, España: Folleto Inmaterial OEI, 2021, Metas Educativas. 
Yajaira Esperanza Araujo Araujo

e-mail: araujoyajairaunica@hotmail.com

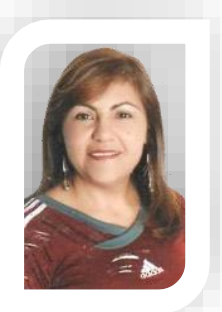

Nacida en Timotes, estado Mérida, Venezuela. Doctora en

Ciencias de la Educación en la UNERMB, estado Trujillo; Magister Scientiarum en Administración de la Educación Básica, UNERMB, estado Trujillo; Licenciada en Educación Integral de la Universidad Cecilio Acosta, estado Trujillo; T.S.U. en Educación Preescolar, IUTMBI, estado Trujillo; Actualmente me desempeño como subdirectora en el NER 196, estado Mérida desde el año 2013. Artículos arbitrados, Jurado de tesis de Pregrado, Postgrado, Asesora de Proyectos en Consejo Comunales.

El contenido de este manuscrito se difunde bajo una Licencia de Creative Commons ReconocimientoNoComercial-Compartirlgual 4.0 Internacional 